\title{
Pengujian Program Mindfulness Singkat untuk Menurunkan Penunda-nundaan Skripsi pada Mahasiswa
}

\author{
Cahyo Setiadi Ramadhan ${ }^{1}$ E Nida Ul Hasanat ${ }^{2}$ \\ Fakultas Psikologi Universitas Gadjah Mada
}

\begin{abstract}
The aim of this study was to test the ability of brief mindfulness-based program on reducing academic procrastination. Hypotheses of this study was that there is difference of declining level of procrastination between participants of program (i.e. experimental group) compared to non-participants (i.e. control group). Students were recruited as participants of study $(\mathrm{N}=21)$ and divided non-randomly into experimental group $(n=11)$ and control group $(n=10)$. For the ethics reason, control group treated as waiting-list. Academic procrastination level was measured by Tes Kegunaan Subjektif Skripsi (TKSS). Data analysis showed there was no significant difference in the TKSS score of experimental group and control group $\left(U=39 ; z=-1,127 ; n_{\mathrm{E}}=11 ; n_{\mathrm{K}}=10 ; p=0,260\right)$. It was clear that brief mindfulness-based program cannot reduce academic procrastination in undergraduate thesis writing.
\end{abstract}

Keywords: academic procrastination; brief mindfulness-based intervention; student

Abstrak. Penelitian ini dimaksudkan untuk menguji kemampuan Program Mindfulness Singkat sebagai terapi untuk menurunkan penunda-nundaan penyelesaian skripsi. Penelitian ini menguji hipotesis bahwa kelompok yang mengikuti program mindfulness singkat mengalami penurunan penunda-nundaan skripsi yang lebih besar dibandingkan kelompok yang tidak mengikuti program. Mahasiswa $(\mathrm{N}=21)$ direkrut menjadi partisipan penelitian kemudian dibagi secara tidak acak ke dalam kelompok eksperimen $(\mathrm{n}=11)$ dan kelompok kontrol $(\mathrm{n}=10)$. Kelompok eksperimen mengikuti program mindfulness singkat dan kelompok kontrol diperlakukan sebagai kelompok tunggu (waiting-list). Penunda-nundaan skripsi partisipan diukur menggunakan Tes Kegunaan Subjektif Skripsi (TKSS). Hasil analisis menunjukkan bahwa tidak ada perbedaan dalam perubahan tingkat penunda-nundaan skripsi kelompok eksperimen dibandingkan kelompok kontrol $\left(U=39 ; z=-1,127 ; n_{\mathrm{E}}=11 ; n_{\mathrm{K}}=10 ; p=0,260\right)$. Hasil tersebut menunjukkan bahwa program mindfulness singkat tidak dapat menurunkan penundanundaan skripsi mahasiswa.

Kata Kunci: intervensi mindfulness singkat; mahasiswa ; mindfulness

Mahasiswa harus menyelesaikan skripsi untuk mendapatkan gelar sarjana dan menamatkan pendidikan strata 1-nya (Idhom, 2015; Peraturan Pemerintah

\footnotetext{
${ }^{1}$ Korespondensi mengenai artikel ini dapat dialakukan melalui: cahyo.setiadi@ugm.ac.id

2 Atau melalui: nida@ugm.ac.id
}

Nomor 60, Pasal 15 ayat 2, 1999). Terdapat mahasiswa yang membutuhkan waktu lama untuk menyelesaikan skripsi, yaitu lebih dari 2 semester, karena penundanundaan pengerjaan skripsi (Djing, 2010; Negara, 2013; Ritonga, 2012; Siaputra, Prawitasari, Hastjarjo, \& Azwar, 2011). Penunda-nundaan pengerjaan skripsi E-JURNAL GAMA JPP 
adalah salah satu bentuk penundanundaan akademik (academic procrastination, Djing, 2010; Negara, 2013; Ritonga, 2012; Siaputra, et al., 2011). Menurut Djing (2010) dan Klingsieck (2013) penunda-nundaan akademik memiliki dinamika yang sama dengan penunda-nundaan secara umum.

Beberapa ciri utama penundanundaan yaitu (1) pelaksanaan tugas terlewat (put off) setelah waktu optimal memulainya (Djing, 2010; Silver dalam Ferrari, Johnson, \& McCown, 1995a, 1995b; Steel, 2002); (2) dilakukan dengan perkiraan dampak yang tidak menguntungkan (Ferrari, et al., 1995a, 1995b; Knaus, 2010; Steel, 2002, 2007); (3) rasa tidak nyaman (psychological pain) (Burka \& Yuen, 2008; Ferrari, dalam Klingsieck, 2013; Rozental \& Carlbring, 2014; Solomon \& Rothblum, 1984); dan (4) kesukarelaan (voluntary) (Ferrari, dalam Klingsieck, 2013; Steel, 2002, 2007).

Terdapat berbagai penjelasan mengenai dinamika kemunculan penunda-nundaan, misalnya pendekatan psikodinamika, behaviorisme, dan cognitive behavioral (Ferrari, et al., 1995b; Rozenthal \& Carlbring, 2014). Salah satu teori baru yang dapat menjelaskan dinamika penunda-nundaan yaitu Temporal Motivation Theory (Burka \& Yuen, 2008; Rozenthal \& Carlbring; Steel, 2007; Steel \& Konig, 2006). Menurut teori tersebut penunda-nundaan bergantung pada kegunaan subjektif tugas yang ditentukan oleh (1) kemungkinan keberhasilan (expectancy); (2) nilai (value) tugas atau keputusan bagi individu. (3) waktu tunda (delay) imbalan; dan (4) kecenderungan mudah teralihkan (impulsivitas; Djing, 2010; Siaputra, et al., 2011; Steel, 2007 \& 2012). Keempat faktor tersebut secara bersamaan menentukan tingkat penunda-nundaan suatu tugas.

Sirois dan Phychyl (2013, 2016) menjelaskan dinamika penunda-nundaan sebagai bagian dari misregulasi emosi dalam regulasi diri. Saat menghadapi tugas yang memunculkan perasaan tidak nyaman, individu cenderung mengutamakan untuk melakukan regulasi emosi, berusaha memunculkan perasaan nyaman. Kondisi ini memunculkan perilaku menghindari tugas atau penundanundaan.

Penunda-nundaan secara umum maupun akademik memiliki tingkat prevalensi yang tinggi (Ozer, Demir, \& Ferrari, 2009). Penunda-nundaan juga memiliki dampak negatif seperti kinerja buruk (Flett, Stainton, Hewitt, Sherry, \& Lay, 2012); pendapatan, waktu, dan status kerja lebih rendah (Nguyen, Steel, \& Ferrari, 2013); tingkat stress dan sakit fisik semakin memburuk (Flett, et al., 2012; Sirois \& Tosti, 2012); dan mental health coping yang jelek sehingga memperburuk kesehatan mental (Ferrari \& Diaz-Morales, 2014; Veresova, 2013). Penunda-nundaan akademik secara khusus juga berpengaruh pada kinerja dan memperburuk tingkat stres dan sakit fisik (Humphrey \& Harbin, 2010; Tice \& Baumeister, 1997).

Prevalensi tinggi dan dampak negatif menjadi argumen Ferrari, dkk. (1995a) mengenai perlunya penelitian tentang penunda-nundaan. Penelitian penunda-nundaan sudah berkembang hingga saat ini namun masih banyak yang perlu dipelajari untuk memahami penunda-nundaan (Steel, 2007). Penelitian tentang intervensi untuk mengatasi penunda-nundaan juga dirasakan masih kurang (Rozenthal \& Carlbring, 2013, 2014). Penelitian mengenai penundanundaan, termasuk penelitian mengenai cara mengatasinya menjadi perlu dilakukan.

Beberapa intervensi untuk menurunkan penunda-nundaan, khusus-nya dalam bidang akademik, telah diteliti. Diantara 
bentuk intervensi yang telah diteliti yaitu sistem hadiah dan deadline (pendekatan perilakuan; Humphrey \& Harbin, 2010), terapi kognitif perilakuan (Ozer, Demir, \& Ferrari, 2013), mental rehearsal (Peper, Harvey, Lin, \& Duvvuri, 2014), dan Belajar Berdasar Regulasi Diri (BBRD; Maulia, 2011). Beberapa penelitian intervensi penunda-nundaan akademik menggunakan intervensi dalam bentuk kelompok (Maulia, 2011; Ozer, dkk., 2013; Rozenthal \& Carlbring, 2013; Rozental, Fosstrom, Nilsson, Rizzo, \& Carlbring, 2014). Para peneliti tersebut memilih untuk mengkaji intervensi penunda-nundaan dalam bentuk kelompok karena menurut mereka intervensi penunda-nundaan akademik perlu dapat dilakukan terhadap banyak individu dalam satu waktu. Kebutuhan tersebut dikarenakan tingginya tingkat kejadian penunda-nundaan akademik (Ozer, et al. 2013).

Salah satu bentuk intervensi psikologis yang dapat dilakukan terhadap banyak individu dalam satu waktu (secara berkelompok) adalah program mindfulness, yaitu melakukan serangkaian praktik mindfulness sebagai terapi (Baer, 2003; Kabat-Zinn, 2003). Praktik mindfulness merupakan usaha untuk menumbuhkan mindfulness. Ciri utama mindfulness yaitu (1) kesadaran (Germer, 2005; Kabat-Zinn, 1994, 2003) atau observasi/mengamati (Baer, 2003; Baer, Smith, \& Allen 2004); (2) terhadap keadaan sekarang (Germer, 2005; Kabat-Zinn, 1994, 2003) atau dinamika internal diri dan eksternal lingkungan (Baer, 2003) (3) disertai sikap tidak mudah menghakimi dan penerimaan (Baer, 2003; Baer, et al., 2004; Kabat-Zinn, 1994, 2003) serta welas asih (friendly) (Germer, 2005).

Program mindfulness telah diteliti dan menunjukkan pengaruh positif terhadap berbagai kondisi psikologis dan kesehatan individu (Kabat-Zinn, 2003). Penelitian mengenai program mindfulness di Indonesia juga menunjukkan manfaat program tersebut seperti meningkatkan kesejahteraan subjektif mahasiswa (Primasari, 2016) dan perawat (Fachrudin, 2016), menurunkan gangguan stres pasca trauma pada penyitas kekerasan dalam rumah tangga (Hartono, 2016), dan menurunkan kecanduan bermain game (Priyudha, 2016). Program mindfulness yang sering menjadi rujukan adalah Mindfulness Stress Based Reduction (MBSR; Baer, 2003; Germer, 2005).

Program mindfulness dapat meningkatkan mindfulness pada individu karena dalam kondisi mindfulness, kesadaran individu meningkat, termasuk sadar akan perasaaannya dan kondisi sekitar yang dihadapinya. Kesadaran tersebut membuat individu mampu melakukan langkah yang sesuai dengan keadaan. Dengan kata lain, individu tidak akan melakukan respon menghindar untuk mendapatkan rasa nyaman, yang merupakan sebab penunda-nundaan (Sirois \& Phychyl, 2013, 2016). Kesadaran melakukan langkah yang sesuai juga menunjukkan penurunan impulsivitas, yaitu salah satu faktor penyebab penundanundaan menurut teori Steel (Steel, 2007, 2012; Steel \& Konig, 2006).

Penjelasan tersebut menunjukkan program mindfulness memungkinkan untuk menjadi salah satu intervensi menurunkan penunda-nundaan, termasuk penunda-nundaan akademik. Namun, Steel (2012) memberi catatan bahwa program mindfulness menurutnya cenderung membosankan dan individu yang melakukan penunda-nundaan cenderung rentan terhadap kebosanan. Pendapat tersebut memunculkan pertimbangan untuk menyusun program mindfulness yang lebih singkat dari yang umumnya dilakukan dalam 8 minggu (Baer, 2003; Germer, 2005).

Program mindfulness berdasarkan 
MBSR dengan waktu lebih singkat dan tidak menggunakan semua praktik dalam MBSR terbukti dapat memberikan dampak positif bagi pesertanya (Fortney, Luchterhand, Zakletskaia, Zgierska, \& Rakel, 2013; Jain, et al., 2007; Kaufman, Glass, \& Arnkoff, 2009; Mackenzie, Poulin, \& Seidman-Carlson, 2006; Zeidan, Johnson, Diamond, David, \& Goolkasian, 2010). Walaupun demikian, sepanjang pengetahuan peneliti, belum ada penelitian yang mengkaji program mindfulness singkat untuk menurunkan penunda-nundaan. Padahal telah ada penelitian yang menunjukkan bahwa program mindfulness (yaitu MBSR) dapat menurunkan penunda-nundaan (Rahimi, Ahmadean, Moslemi, Ghaderi, \& Khoshroei, 2014). Penelitian ini berusaha memenuhi kebutuhan tersebut dengan melakukan kajian mengenai program mindfulness singkat untuk menurunkan penunda-nundaan.

\section{Metode}

\section{Rancangan}

Rancangan penelitian yang digunakan yaitu Untreated Control Group Design with Dependent Pretest and Posttest Samples. Partisipan penelitian dibagi menjadi dua kelompok yaitu kelompok eksperimen (KE) yang mengi-kuti program dan kelompok kontrol (KK) yang tidak dikenai intervensi apapun. Anggota KK mendapatkan kesempatan mengikuti program mindfulness setelah penelitian selesai (waiting-list).

\section{Partisipan}

Partisipan penelitian ini yaitu mahasiswa Fakultas Psikologi Universitas Gadjah Mada (UGM), (2) memiliki waktu penyelesaian skripsi lebih dari dua semester, (3) memiliki tingkat penundanundaan skripsi tinggi atau sedang, (4) tertarik mengikuti program/intervensi psikologis, (5) tidak sedang menjalani intervensi psikologis mengatasi penundanundaan, serta (6) dapat berfungsi dalam kehidupan sehari-hari. Perekrutan dilakukan dengan menawarkan Program Mindfulness melalui surat elektronik dan short messege service.

Pendaftar yang direkrut menjadi partisipan adalah 22 orang. Dua puluh satu orang dari partisipan tersebut adalah pendaftar yang memenuhi kriteria penelitian. Satu orang partisipan adalah pendaftar yang telah mengerjakan skripsi dalam dua semester. Walaupun demikian, partisipan tersebut menilai dirinya sendiri lambat atau menunda-nunda dalam pengerjaan skripsi. Selain itu, tingkat penunda-nundaan skripsinya dalam kategori sedang sehingga partisipan tersebut diikutsertakan dalam penelitian.

\section{Instrumen}

Instrumen yang digunakan dalam penelitian ini adalah Tes Kegunaan Subjektif Skripsi (TKSS), Buku Fasilitator Program, Buku Peserta Program, dan Kentucky Inventory of Mindfulness Skills (KIMS).

Tes Kegunaan Subjektif Skripsi (TKSS) disusun oleh Djing (2010; Siaputra, dkk., 2011) untuk mengukur tingkat penunda-nundaan skripsi berdasarkan Temporal Motivation Theory (Steel, 2007; Steel \& Konig, 2006). Skala ini memiliki indeks reliabilitas 0,775 dan konsistensi internal sebesar 0,843 dalam pengujian pada 232 responeden (Djing, 2010). Contoh aitem TKSS untuk mengukur harapan keberhasilan (expectancy) yaitu "Saya dapat mengerjakan bagian latar belakang (bab 1) dengan cepat."

Buku Fasilitator Program adalah modul/panduan intervensi yang peneliti susun dan dijelaskan lebih detail pada bagian Intervensi. Buku Peserta Program 
juga disusun oleh peneliti dan terdiri dari: (1) jurnal peristiwa harian sebagai laporan diri tentang kejadian keseharian partisipan di luar intervensi, (2) jurnal praktik harian yaitu laporan diri tentang latihan mandiri di luar program, dan (3) catatan/tulisan tentang materi/ informasi dalam program.

Kentucky Inventory of Mindfulness Skills (KIMS) adalah Instrumen Tambah-an yang digunakan untuk memperkaya pembahasan dan cek manipulasi. Skala tersebut disusun oleh Baer, Smith, \& Allen (2004) untuk mengukur kecenderungan mindfulness seseorang yang terdiri dari empat komponen yaitu mengamati (observing), mendes-kripsikan hasil amatan (describing), berlaku dengan kesadaran (acting with awareness), dan menerima tanpa prasangka (accepting without judgment). Skala yang digunakan dalam penelitian ini adalah skala yang telah diterjemahkan oleh Widyatmoko (2010) dengan Alpha Cronbach 0,752. Contoh aitem KIMS terjemahan yaitu "Aku menyadari perubahan pada tubuhku, seperti nafasku melambat atau menjadi lebih cepat." Instrumen tambahan lainnya adalah Lembar Observasi Partisipan
Program, Lembar Observasi Umum, dan Lembar Indikator Keberhasilan Program yang penulis susun sendiri. Lembar ini diisi oleh pengamat (observer).

\section{Intervensi}

Intervensi dalam penelitian ini merupakan program mindfulness singkat. Program mindfulness mengacu kepada MBSR, yaitu menggunakan praktik mindfulness dan urutan praktik berdasarkan MBSR (KabatZinn, 1993, 2005; Stahl \& Goldstein, 2009). Namun, tidak semua praktik dalam MBSR dicontoh karena pertimbangan kepraktisan dan kemungkinan pelaksanaannya. Kondisi tersebut menjadikan program mindfulness penelitian ini dapat dilakukan dalam empat pertemuan, lebih pendek daripada MBSR. Rincian kegiatan intervensi disusun dalam Buku Fasilitator Program sebagai modul/ panduan intervensi.

Buku Fasilitator telah direviu 5 orang ahli dengan kriteria: (1) melakukan penelitian dan mempelajari mindfulness, (2) pernah menyusun panduan program mindfulness, serta (3) telah menamatkan atau sedang menempuh tahun akhir

Tabel 1.

Rangkaian kegiatan program mindfulness

\begin{tabular}{lll}
\hline Pertemuan & & \\
\hline Ke-1 & 1. & Perkenalan \\
& 2. & Penjelasan Program \\
& 3. & Mindful Check-in \\
& 4. & Diskusi Definisi, Manfaat, dan Latihan Mindfulness \\
& 5. & Praktik Mindfulness Nafas \\
& 6. & Tugas Praktik \\
\hline Ke-2 & 1. & Diskusi Mindfulness Untuk Keselarasan Tubuh dan Pikiran \\
& 2. & Praktik Mindfulness Tubuh \\
& 3. & Tugas Praktik dan Penjelasan STOP. \\
\hline Ke-3 & 1. & Diskusi “Praktik Mindfulness Semakin Dalam” \\
& 2. & Praktik Mindfulnesss Duduk \\
& 3. & Tugas Praktik dan Penjelasan RAIN \\
\hline Ke-4 & 1. & Diskusi “Cinta Kasih Mentranformasi Ketakutan” \\
& 2. & Praktik Mindfulnesss Cinta Kasih \\
& 3. & Psikoedukasi “Meneruskan Manfaat Mindfulness" \\
& 4. & Terminasi \\
\hline
\end{tabular}


pendidikan magister profesi psikologi bidang klinis. Para ahli tersebut menilai bahwa rata-rata kegiatan Buku Fasilitator cukup sesuai untuk meningkatkan mindfulness $(V=0,7-0,9)$. Buku Fasilitator juga diujicobakan kepada 8 mahasiswa tingkat akhir pada 22 - 26 Desember 2016. Dua pengamat $(\mathrm{k}=0,92)$ menilai $92 \%$ kegiatan ujicoba sesuai rencana. Mindfulness peserta ujicoba tersebut meningkat setelah program $(T=0, n=8, p$ $<0,05)$. Rangkaian kegiatan intervensi terdapat pada Tabel 1.

\section{Prosedur}

Eksperimenter/fasilitator dalam penelitian ini merupakan profesional yang (1) berpengalaman mengikuti MBSR atau program mindfulness yang menjadikan MBSR sebagai acuan, (2) melakukan praktik mindfulness rutin, (3) psikolog bidang klinis, (4) berpengalaman menjadi fasilitator praktik mindfulness, dan (5) berpengalaman menjadi fasilitator kelompok remaja atau mahasiswa. Pengamat (observer) dalam penelitian adalah seorang psikolog dan seorang mahasiswa tingkat akhir Magister Psikologi Profesi UGM bidang klinis.

Partisipan berjumlah 22 orang yang dibagi menjadi -11 orang di kelompok eksperimen (KE) dan 11 orang di kelompok kontrol (KK) berdasarkan keluangan waktu mengikuti program (non random assigment). Amatan pertama (pretest) yaitu kedua kelompok mengerjakan TKSS dan KIMS bersamaan yaitu di akhir rekrutmen. Tidak terdapat perbedaan kondisi penunda-nundaan $(U=$ 39; $z=-1,127 ; p=0,260)$ dan kondisi mindfulness $(U=44,5 ; z=-0,741 ; p=0,459)$ antara KK $(n=10)$ maupun KE $(n=11)$. Semua skor TKSS partisipan $(M d n=50,33)$ berada pada tingkatan sedang atau rendah
$(M$ teoritis $=50 ; S D=10 ; X<70)$. Hal tersebut menunjukkan kondisi penundanundaan semua partisipan pada tingkatan sedang atau tinggi.

Pelaksanaan Intervensi yaitu KE mengikuti intervensi program mindfulness berdasarkan Buku Fasilitator dan KK tidak mendapatkan perlakuan. Intervensi dilaksanakan di Fakultas Psikologi UGM. Dalam pertemuan kedua hingga keempat, terdapat partisipan yang terlambat dan juga tidak hadir. Partisipan yang tidak hadir mengikuti pertemuan susulan yang dilaksanakan sesuai Buku Fasilitator. Dua pengamat $(\mathrm{k}=0,96)$ dan semua partisipan KE menilai (ICC $=0,38$ ) performa fasilitator serta kondisi ruang pertemuan memadai untuk pelaksanaan program. Hal yang dikritik yaitu kursi pertemuan pertama kurang nyaman untuk praktik mindfulness serta ketepatan jam intervensi. Amatan kedua (Post-test) yaitu KK dan KE mengisi TKSS dan KIMS kembali setelah program terhadap KE selesai. Satu partisipan KK tidak dapat mengerjakan TKSS dan KIMS karena sakit dan dianggap gugur. Oleh karena itu, data yang dapat dianalisis setelah intervensi adalah 10 partisipan KK dengan 11 partisipan KE.

\section{Hasil}

Uji asumsi menunjukkan skor mindfulness KE pre-test tidak terdistribusi berdasarkan kurve normal dengan $\mathrm{D}(11)=0,291, p=$ 0,01 . Selain itu, menurut Sani dan Todman (2006), jumlah partisipan 21 orang merupakan jumlah kritis untuk melakukan analisis statistik parametrik. Hal ini menjadikan analisis yang digunakan adalah statistik non parametrik. 
Analisis Mann-Withney $U$ terhadap data penunda-nundaan partisipan menunjukkan tidak ada perbedaan yang signifikan antara perubahan kondisi penunda- $\left.z=-3 ; n_{\mathrm{E}}=11 ; n_{\mathrm{k}}=10 ; p=0,03\right)$. Kelompok eksperimen $(M d n=12)$ mengalami peningkatan kondisi mindfulness yang lebih besar dibandingkan dengan KK

Tabel 2.

Perbandingan perubahan komponen penunda-nundaan kelompok kontrol dan eksperimen mindfulness

\begin{tabular}{|c|c|c|c|c|c|}
\hline Komponen & $U$ & Z & $n_{\mathrm{E}}$ & $n_{\mathrm{K}}$ & $p$ \\
\hline Harapan & 30 & $-1,814$ & 11 & 10 & 0,07 \\
\hline Nilai & 40 & $-1,064$ & 11 & 10 & 0,287 \\
\hline $\begin{array}{l}\text { Kepekaan Pada } \\
\text { Penundaan }\end{array}$ & 50,5 & $-0,324$ & 11 & 10 & 0,746 \\
\hline Waktu Tunda & 39 & $-1,177$ & 11 & 10 & 0,239 \\
\hline
\end{tabular}

Keterangan: $U=$ koefisien hasil perhitungan Mann-Whitney $U$ perbedaan KE dan KK.. $\mathrm{z}=z$-score atau penyimpangan nilai $\mathrm{U}$ dari mean $\mathrm{U}, \mathrm{nK}_{\mathrm{K}}=$ jumlah sub-sampel $\mathrm{K}$ (kontrol), $\mathrm{nE}_{\mathrm{E}}=$ jumlah sub-sampel $\mathrm{E}$ (eksperimen). $p=$ probability value ( $p$-value) atau signifkansi tes Mann-Whitney $U$.

nundaan skripsi KE dan perubahan kondisi penunda-nundaan skripsi KK antara amatan pertama dan kedua $(U=39$; $\left.z=-1,127 ; n_{\mathrm{E}}=11 ; n_{\mathrm{k}}=10 ; p=0,26\right)$. Dengan demikian, hipotesis penelitian ditolak. Perubahan kondisi penunda-nundaan yang terjadi pada partisipan tidak ditentukan oleh keikutsertaan dalam program mindfulness singkat. Effect size kondisi tersebut kecil (ES = -0,246).

Cek manipulasi (manipulation check) juga dilakukan dengan penilaian oleh pengamat menggunakan lembar observasi untuk mengetahui pelaksanaan intervensi. Dua pengamat $(\mathrm{k}=0,96)$ menilai $96 \%$ yang berarati program mindfulness berjalan sesuai yang diharapkan. Analisis Mann-
$(M d n=-1,00)$. Hasil tersebut menunjukkan bahwa individu yang mengikuti program mindfulness mengalami peningkatan kondisi mindfulness yang lebih besar secara signifikan dibandingkan kelompok kontrol. Dapat dikatakan, program mindfulness dalam penelitian lebih meningkatkan kondisi mindfulness pesertanya. Effect size kondisi tersebut cukup besar $(\mathrm{ES}=-0,654)$.

Analisis menunjukkan tidak terdapat perbedaan yang signifikan dalam perubahan komponen penunda-nundaan KE dibandingkan dengan KK. Hasil analisis Mann-Whitney $U$ terhadap perubahan komponen-komponen penundanundaan dapat dilihat pada Tabel 2.

Tabel 3.

Perbandingan perubahan komponen mindfulness kelompok kontrol dan eksperimen

\begin{tabular}{lrcccc}
\hline Komponen & $U$ & $Z$ & $n_{\mathrm{E}}$ & $n_{\mathrm{K}}$ & $p$ \\
\hline Observing & 21,5 & $-2,369$ & 11 & 10 & 0,018 \\
\hline Describing & 18,5 & $-2,593$ & 11 & 10 & 0,01 \\
\hline Acting With Awareness & 34,5 & $-1,452$ & 11 & 10 & 0,146 \\
\hline Accept Without Judgment & 47,5 & $-0,530$ & 11 & 10 & 0,596 \\
\hline
\end{tabular}

Withney $U$ terhadap data mindfulness partisipan menunjukkan ada perbedaan signifikan dalam perubahan kondisi mindfulness KK dibandingkan KE setelah mengikuti program mindfulness. $(U=12,5$;
Analisis Mann-Whitney $U$ terhadap perubahan (gain score) komponen mindfulness KE dan KK menunjukkan bahwa terdapat dua komponen mindfulness yang menunjukkan perbedaan 
signifikan dalam perubahan antara KE dan KK. Komponen tersebut adalah observing (mengamati) dan describing (mendeskripiskan). Komponen acting with awarness (berbuat dengan kesadaran) dan accept without judgemental (berbuat tanpa judgemental) tidak menunjukkan perbedaan perubahan antara KK dan KE setelah intervensi. Hasil analisis Mann-Whitney $U$ terhadap perubahan komponenkomponen penunda-nundaan dapat dilihat pada Tabel 3 .

Hasil tersebut menunjukkan bahwa perubahan komponen bertindak dengan kesadaran dan tanpa judgemental tidak di-

tentukan oleh keikutsertaan dalam program mindfulness (intervensi/ manipulasi). Tingkat perubahan komponen mengamati dan mendeskrip-sikan ditentukan oleh keikutsertaan dalam program intervensi. Kelompok KE yang mengikuti intervensi mengalami kenaikan lebih besar dalam komponen mengamati $(M d n=5)$ dibandingkan $\mathrm{KK}(M d n=0)$. Demikian juga dalam komponen mendeskripsikan, KE mengalami kenaikan yang lebih besar $(M d n=2)$ dibandingkan KK $(M d n=-1,4)$. Effect size kondisi ini cukup besar yaitu $-0,517$ untuk perubahan komponen mengamati dan -0,566 untuk komponen mendeskripsikan. Program mindfulness dalam penelitian ini cukup mampu memperbesar peningkatan kemampuan individu untuk mengamati dan juga mendeskripsikan kondisi yang terjadi di dalam maupun luar dirinya.

Peningkatan describing yang ditimbulkan program mindfulnes dalam penelitian ini tidak menjadikan kemampuan KE untuk mendeksripsikan diri dan kondisinya berbeda secara signifikan dibandingkan $\mathrm{KK}\left(U=48,5 ; z=-0,461 ; n_{\mathrm{E}}=\right.$ $\left.11 ; n_{\mathrm{k}}=10 ; p=0,645\right)$. Hasil ini menunjukkan walaupun program mindfulness dapat memperbesar peningkatan kemampuan KE untuk mendeskrip- sikan diri dibandingkan KK yang tidak mengikuti program, namun peningkatan tersebut belum dapat mengubah kategori kemampuan mendeskripsikan KE.

Peningkatan kemampuan observing berbeda dengan kondisi peningkatan kemampuan mendeskripsikan. Peningkatan kemampuan KE untuk mengamati kondisi dirinya setelah program mindfulness dapat menjadikan kemampuan mereka berbeda secara signifikan dibandingkan individu yang tidak mengikuti program $(U=26,5 ; z=-2,011 ; n \mathrm{E}$ $\left.=11 ; n_{\mathrm{k}}=10 ; p<0,044\right)$. Kategori kemampuan mengamati diri KK berdasarkan standar yang ditetapkan peneliti $(M$ teoritis $=36 ; S D=4,8 ; X<45,6)$ dapat berubah setelah mengikuti program mindfulness. Kemapuan mengamati KE meningkat dari kategori sedang $(M d n=39)$ menjadi mendekati kategori tinggi $(M d n=$ 43). Kelompok Kontrol tetap berada pada kategori sedang $(M d n=35)$.

\section{Diskusi}

Hipotesis yang diajukan dalam penelitian ditolak berdasarkan analisis statistik. Individu yang mengikuti program mindfulness singkat tidak mengalami penurunan penunda-nundaan dibandingkan dengan individu yang tidak mengikuti program. Perubahan kondisi penunda-nundaan yang terjadi pada partisipan tidak ditentukan oleh faktor ikut atau tidaknya mereka dalam intervensi. Hasil penelitian ini menunjukkan program mindfulness singkat tidak dapat menurunkan penunda-nundaan, berbeda dengan program mindfulness dalam 8 pertemuan yang dapat menurunkan penunda-nundaan pada perawat (Rahimi, dkk., 2014).

Faktor metode yaitu alat ukur, fasilitator, panduan intervensi (manipulasi), dan partisipan dapat 
memengaruhi hasil penelitian. Alat ukur penunda-nundaan skripsi berupa TKSS menunjukkan validitas dan reliabilitas yang baik (Djing, 2010; Siaputra, et al., 2011). Alat ukur KIMS diterjemahkan secara baik (Widyatmoko, 2010), digunakan pada berbagai penelitian (Fachrudin, 2016; Hartono, 2016), dan menunjukkan reliabilitas memadai. Program mindfulness dalam penelitian telah difasilitasi oleh eksperimenter secara memadai menurut penilaian pengamat $(\mathrm{k}$ $=0,96)$ dan partisipan $(\mathrm{ICC}=0,38)$.

Panduan program mindfulness juga telah dinilai sesuai untuk meningkatkan mindfulness oleh 5 orang panel ahli. Program berdasar rancangan tersebut meningkatkan mindulness peserta uji coba. Cek manipulasi penelitian menunjukkan bahwa hasil program sesuai dengan tujuannya yaitu program mindfulness memengaruhi peningkatan kondisi mindfulness peserta. Hasil ini sesuai dengan penelitian sebelumnya seperti Bränström, dkk. (2010) atau Carmody dan Baer (2008) yaitu program mindfulness dapat meningkatkan kondisi mindfulness pesertanya.

Kondisi mindfulness yang meningkat namun kondisi penunda-nundaan yang tidak menurun dalam penelitian ini sejalan dengan hasil penelitian Rice, Nimeyer, dan Taylor (2011). Penelitian tersebut menemukan bahwa Coherence Therapy yang secara eksplisit dimaksudkan untuk mengatasi penunda-nundaan tidak mengubah kondisi penunda-nundaan secara signifikan dan justru mengubah kondisi yang melatarbelakangi penunda-nundaan yaitu perfeksionisme. Menurut Rice, dkk. perubahan penunda-nundaan terjadi tetapi membutuhkan waktu lama untuk dapat teramati. Program mindfulness dalam penelitian ini dilaksanakan dalam waktu yang lebih pedek daripada MBSR yang sering menjadi acuan waktu pelaksanaan program mindfulness.

Faktor waktu yang pendek dapat memengaruhi hasil program mindfulness yaitu komponen penerimaan dalam mindfulness tidak meningkat (Fachrudin, 2016). Analisis tiap komponen mindfulness menunjukkan program mindfulness dalam penelitian ini paling berpengaruh pada peningkatan kemampuan mengamati (observing). Selain itu, komponen mendeskripsikan (describing) juga mengalami perubahan signifikan pada KE dibandingkan KK. Kondisi ini mungkin dapat menjelaskan hasil penelitian.

Menurut Glick, et al. (2014) kondisi kesadaran saja tidak akan memengaruhi kondisi penunda-nundaan individu. Bahkan, kesadaran tanpa diiringi oleh penerimaan dapat memunculkan dampak yang merusak. Misalnya penelitian Nicholson dan Scharff (2007) menunjukkan bahwa kesadaran diri justru memunculkan emosi negatif pada penunda-nunda. Penerimaan merupakan komponen dalam mindfulness yang berhubungan negatif dengan penunda-nundaan (Sirois \& Tosti, 2012). Hal ini sesuai dengan berbagai penelitian yang menunjukkan perlunya penerimaan (Barnard \& Curry, 2011; Sirois, 2014) atau memaafkan diri sendiri (Wohl, Pychyl, \& Bennet, 2010; Peper, dkk., 2014) untuk menurunkan penunda-nundaan. Menurut Glick, dkk. (2014), komponen mindfulness yang signifikan dalam menentukan penundanundaan selain menerima tanpa prasangka (accepting without judgment) yaitu mendeskripsikan hasil amatan (describing) serta berlaku dengan kesadaran (acting with awareness).

Komponen mengamati saja juga tidak memengaruhi komponen penundanundaan dalam teori motivasi temporal, seperti impulsivitas (Peters, Erisman, Upton, Baer, \& Roemer, 2011) dan efikasi diri mengatasi stres (Luberto, Cotton, 
McLeish, Mingione \& O’Bryan, 2014). Penelitian Peters, dkk. menunjukkan bahwa impulsivitas justru berhubungan negatif dengan komponen mindfulness selain mengamati, yaitu deskripsi, aksi berkesadaran, dan penerimaan. Penelitian Wei, Tsui, Lannin, Du, dan Tucker (2015) juga menunjukkan bahwa penerimaan penting dalam dinamika hubungan positif mindfulness dengan efikasi konseling. Dapat dikatakan bahwa komponen mengamati memerlukan komponen mindfulness lain khususnya penerimaan untuk menurunkan impulsivitas dan meningkatkan efikasi diri seseorang mengenai sebuah tugas.

Komponen penerimaan juga merupakan kondisi yang menentukan peningkatan regulasi emosi (Jimenez, Niles, \& Park, 2010). Penelitian Short, Mazmanian, Oinonen, dan Mushquash (2016) menunjukkan bahwa regulasi emosi berhubungan positif dengan komponen mengamati dan penerimaan dalam mindfulness. Regulasi emosi tersebut merupakan hal yang penting dalam dinamika penunda-nundaan (Sirois \& Pychyl, 2013, 2016). Hal tersebut menjadikan penerimaan juga penting dalam dinamika terjadinya penundanundaan menurut Sirois dan Pychyl tersebut.

Penjelasan tersebut mengarahkan pada pemikiran bahwa komponen mengamati perlu ada bersama komponen mindfulness lainnya agar kondisi mindfulness dapat memengaruhi atau menurunkan penunda-nundaan. Penelitian de Bruin, Topper, Muskens, Bögels, dan Kamphuis (2012) mendukung hal tersebut. Penelitian mereka menunjukkan bahwa komponen mengamati dan mendeskripsikan saja tidak dapat mengubah kondisi psikologis individu. Desrosiers, Vine, Curtiss, dan Klemanski (2014) menunjukkan bahwa kemampuan mengamati diri perlu disertai dengan kemampuan tidak reaktif agar mindfulness dapat memengaruhi kondisi psikologis individu.

Hasil penelitian ini melengkapi hasil penelitian sebelumnya tentang waktu pelaksanaan program mindfulness. Menurut Carmody dan Baer (2007) lama pelaksanaaan program tidak memiliki pengaruh pada penurunan simtom psikologis yang hendak diatasi dengan program mindfulness tersebut. Terdapat juga berbagai penelitian lain yang menunjukkan bahwa program mindfulness yang dilaksanakan dalam waktu singkat dapat memunculkan manfaat mindfulness (Fortney, et al., 2013; Jain, et al., 2007; Kaufman, et al., 2009; Mackenzie, et al., 2006; Zeidan, et al., 2010). Di sisi lain, penelitian ini dan Fachruddin (2016) menunjukkan bahwa waktu atau durasi program menjadi faktor yang perlu diperhatikan dalam penyusunan program mindfulness. Dapat dikatakan bahwa waktu pelaksanaan program mindfulness perlu menyesuaikan dengan tujuan yang hendak dicapai. Program mindfulness untuk mengatasi penunda-nundaan perlu memperhatikan faktor waktu untuk meningkatkan komponen penerimaan.

Hasil penelitian ini dan Fachrudin (2016) menunjukkan bahwa komponen mengamati merupakan komponen mindfulness yang paling terlihat perubahannya setelah individu mengiktu program mindfulness. Hal ini sesuai dengan berbagai penjelasan para ahli tentang mindfulness. Menurut para ahli, mindfulness identik dengan pengamatan (Baer, 2003; Germer, 2005; Kabat-Zinn 1994, 2003; Tang \& Posner, 2015; Watkins, 2015). Identitas tersebut menurut Fachrudin menjadikan program mindfulness paling dapat memengaruhi secara positif komponen mengamati (observing).

Penjelasan tersebut sesuai dengan 
pendapat VanVaugt (2015) bahwa mindfulness dimulai dari pengamatan tentang kondisi sekitar (focused attention) yang dikembangkan dengan penerimaan menjadi kesadaran yang terbuka (open awareness). Urutan tersebut tidak berbeda dengan yang dikemukakan oleh Germer (2005) dan Szabo, et al. (2015), bahwa mindfulness didahului dengan perhatian yang diperkaya dengan sikap termasuk penerimaan. Penjelasan tersebut menunjukkan bahwa untuk meningkatkan penerimaan terhadap diri diperlukan waktu program yang lebih panjang, kemungkinan delapan minggu dengan kelas/pertemuan selama dua jam setiap minggu sebagaimana MBSR.

Faktor latihan peserta juga patut menjadi perhatian sebagaimana yang dikemukakan Fachrudin (2016). Penelitian Carmody \& Baer (2007) menunjukkan bahwa praktik mindfulness di rumah dapat lebih meningkatkan mindfulness peserta program. Semakin banyak melakukan praktik mindfulness semakin meningkatkan kemampuan mindfulness, termasuk dalam kehidupan sehari-hari (Holzel, et al., 2008; Lykins \& Baer, 2009). Dalam penelitian ini, peserta telah dihimbau untuk melakukan praktik mandiri di rumah, tetapi himbauan tersebut tidak dapat mendorong peserta untuk melakukan praktik. Perlu dipertimbangkan untuk mewajibkan latihan rumah kepada peserta. Pendataan praktik peserta juga perlu menjadi perhatian.

Berbagai penjelasan tersebut dilakukan dengan membandingkan hasil penelitian ini dengan penelitian lainnya dan menunjukkan bahwa hasil penelitian ini dapat dijelaskan dan sejalan dengan berbagai hasil penelitian sebelumnya. Walaupun demikian, aplikasi hasil penelitian ini pada keadaan, tempat, atau waktu lain harus dengan memperhatikan berbagai kondisi dalam penelitian ini.
Desain Untreated Control Group Design with Dependent Pretest and Posttest Samples meminimalkan penjelasan ambigu tentang sebab-akibat (causal ambiguity) karena dapat menunjukkan bahwa perubahan yang terjadi hanya dikarenakan intervensi (Campbell \& Stanley, 1967; Finger \& Rand, 2003). Walaupun demikian, bias seleksi, bias instrumen, dan bias regresi masih perlu diperhatikan agar penelitian ini menghasilkan kesimpulan yang kemungkinan besar benar (Shadish, Cook, \& Campbel, 2002). Kondisi tersebut berusaha diatasi dengan memastikan kesetaraan KE dan KK, menetapkan kriteria seleksi yang mengakomodasi kelompok dengan kategori sedang, serta menggunakan alat ukur yang valid dan reliabel. Alat ukur yang valid dan reliabel akan mengatasi ancaman bagi kesahihan hasil secara statistik dan internal (local molar validity), dan construct karena pengukuran berulang yang memungkinkan perubahan skor hanya dikarenakan menghadapi tes yang sama.

Peneliti juga mempelajari konstrak yang diteliti melalui telaah pustaka, memotivasi peserta dalam mengisi skala, menggunakan masking procedure, memberi keleluasaan pada partisipan, dan menyediakan perlakuan setara bagi kedua kelompok untuk menjaga kesahihan hasil dari segi teori. Peneliti juga melakukan berbagai usaha lain secara umum untuk mengatasi hal-hal yang dapat mengancam kesahihan penyimpulan (Shadish, et al., 2002) yaitu menggunakan alat ukur yang valid dan reliabel, memenuhi tuntutan asumsi uji statistik, melaksanakan intervensi (manipulasi) secara setara bagi semua KK, menjaga lingkungan pelaksanaan intervensi, dan merekrut partisipan dari kelompok yang setara.

Peneliti meminta partisipan menuliskan pengalaman keseharian untuk mendata hal di luar penelitian yang 
mungkin memengaruhi hasil. Walaupun demikian, KK tidak mendapatkan tugas yang sama dan tidak semua KE menerangkan secara lengkap kejadian kesehariannya. Peneliti juga berusaha agar KK tidak tercampur dengan KE dengan meminta partisipan untuk menjaga kerahasiaan semua proses dalam penelitian untuk mencegah terjadinya treatment difussion (Shadish, Cook, \& Campbel, 2002).

\section{Kesimpulan}

Program mindfulness singkat dalam penelitian ini tidak memengaruhi penurunan penunda-nundaan skripsi. Program mindfulness menunjukkan pengaruh positif terhadap kondisi mindfulness secara umum, namun tidak meningkatkan kondisi semua komponen mindfulness. Hal tersebut menjelaskan tidak adanya perubahan pada komponen penundanundaan skripsi dan kondisi penundanundaan skripsi tidak menurun. Selain itu, program mindfulness dalam penelitian ini belum memperhatikan secara khusus mengenai komponen penerimaan (acceptance) dalam mindfulness serta kondisi regulasi emosi.

Hal-hal tersebut perlu diperhatikan dalam perumusan program mindfulness, khususnya untuk mengatasi penundanundaan. Langkah yang dapat dilakukan untuk memastikan peningkatan kondisi penerimaan (acceptance) peserta dalam program mindfulness yaitu merancang waktu pelaksanaan program sesuai MBSR, dua jam pertemuan setiap pekan dalam delapan pekan. Selain itu, peserta juga perlu diwajibkan melakukan latihan mandiri di rumah.

\section{Saran}

Terdapat beberapa rekomendasi yang dapat peneliti ajukan. Penelitian selanjutnya tentang mindfulness dan penunda-nundaan perlu memperhatikan komponen penerimaan dalam mindfulness dan regulasi emosi. Rancangan intervensi mindfulness untuk mengatasi penundanundaan secara umum maupun dalam penelitian selanjutnya juga perlu memperhatikan komponen penerimaan dalam mindfulness, menyesuaikan waktu pelaksanaannya untuk meningkatkan komponen tersebut, dan mewajibkan praktik di rumah. Selain itu, rancangan penelitian penunda-nundaan selanjutnya hendaknya menggunakan follow up mengantisipasi perubahan penundanundaan yang membutuhkan proses dalam waktu lama. Kepada partisipan penelitian maupun individu yang melakukan penunda-nundaan secara umum disarankan untuk meningkatkan penerimaan dalam dirinya.

\section{Kepustakaan}

Baer, R. A (2003) Mindfulness training as a clinical intervention: A conceptual and empirical review. Clinical Psychology Science \& Practice,10: 125143. doi: 10.1093/clipsy/bpg015.

Baer, R. A., Smith, G.T., \& Allen, K. B. (2004) Assesment of mindfulnesss by self repost: The Kentucky inventory mindfulness skill. Assesment,11: 191 206. doi: $10.1177 / 1073191104268029$

Barnard, L.K. and Curry, J.F. (2011) SelfCompassion: Conceptualizations, Correlates, and Interventions. Review of General Psychology, 15, 289-303. doi: 10.1037/a0025754.

Bränström, R., Kvillemo, P., Brandberg, Y., \& Moskowitz, J. T. (2010) Self-report mindfulness as a mediator of psychological well-being in a stress reduction intervention for cancer patients-A randomized study. Annals of Behaviroal Medicine, 39: 151161. doi: 10.1007/s12160-010-9168-6. 
Burka, J. B., \& Yuen, L. M. (2008) Procrastination: Why you do it, what to do about it now (rev. ed.) Cambrige: Da Capo Press.

Campbell, D.T. \& Stanley, J.C. (1966). Experimental and quasi-experimental designs for research. Chicago: RandMcNally.

Carmody, J., \& Baer, R. A (2007) Relationships between mindfulness practice and levels of mindfulness, medical and psychological symptoms and well-being in a mindfulness-based stress reduction program. Journal of Behavioral Medicine, doi: 10.1007/s10865-0079130-7.

Carmody, J., \& Baer, R. A. (2008). Relationships between mindfulness practice and levels of mindfulness, medical and psychological symptoms and well-being in a mindfulness-based stress reduction program. Journal of Behavioral Medicine, 31, 23-33. doi: 10.1007/s10865-007-9130-7.

Desrosiers, A., Vine, V., Curtiss, J., \& Klemanski, D. H. (2014). Observing non-reactively: A conditional process model linking mindfulness facets, cognitive emotion regulation strategies, and depression and anxiety symptoms. Journal of Affective Disorders, 165: 31-37

Djing, S. T. (2010). Pengembangan alat ukur penunda-nundaan pengerjaan skripsi. (Desertasi). Universitas Gadjah Mada, Yogyakarta.

De Bruin, E L., Topper, M., Muskens, J. G. A. M., Bögels, S. M., \& Kamphuis, J. H. (2012) Psychometric properties of the five facets mindfulness questionnaire (ffmq) in a meditating and a non-meditating sample. Assessment, 19(2): 187-197.

Fachrudin, D. (2016) Program mindfulness untuk meningkatkan kesejateraan subjektif perawat. (Tesis) Universitas Gadjah Mada, Yogyakarta.

Ferrari, J. R., \& Díaz-Morales, J. F. (2014). Procrastination and mental health coping: A brief report related to students. Individual Differences Research, 12(1): 8-11. ISSN: 1541-745X

Ferrari, J. R., Johnson, J. L., \& McCown, W. G. (1995a) An overview of procrastination. Dalam penulis (Eds) Procrastination and task avoidance: Theory, research, and treatment. New York: Springer.

Ferrari, J. R., Johnson, J. L., \& McCown, W. G. (1995b) Procrastination research: A synopsis of existing research perspectives. Dalam penulis (Eds) Procrastination and task avoidance: Theory, research, and treatment. New York: Springer.

Flett, G. L., Stainton, M, Hewitt, P. L., Sherry, S. B., \& Lay, C. (2012) Procrastination automatic thoughts as a personality construct: An analysis of the procrastinatory cognitions inventory. Journal of Rational-Emotive \& CognitiveBehavioral Therarpy. doi 10.1007/s10942-012-0150-z.

Finger, M. S., \& Rand, K. L. (2003). Chapter two: Addressing validity concerns in clinical psychology research. Dalam Michael C. Roberts, M. V. \& Ilardi, S. S.,(Ed) Handbook of research methods in clinical psychology. (hal. 13 - 30) Malden, MA: Blacwell Publishing.

Fortney, L., Luchterhand, C., Zakletskaia, L., Zgierska, A., \& Rakel, D. (2013). Abbreviated mindfulness intervention for job satisfaction, quality of life, and compassion in primary care clinicians: A pilot study. Annals of Family Medicine, 11(5): 412 - 420. doi:10.1370/afm.1511.

Germer, C. K (2005) Mindfulness: What is 
it? What does it matter? Dalam Germer, C. K., Siegel, R. D., \& Fulton, P. R. (Ed.) Mindfulness and psychotherapy (1 ${ }^{\text {st }}$ ed.) (hal 3-27). New York, NY: Guilford Press.

Glick, D. M., Millstein, D. J., \& Orsillo, S. M. (2014) A preliminary investigation of the role of psychological inflexibility in academic procrastination. Journal of Contextual Behavioral Science, 3:81-88. doi: 10.1016/j.jcbs.2014.04.002.

Hartono, V. E. K. (2016) Program peningkatan regulasi diri berbasis mindfulness untuk menurunkan gangguan stres pasca trauma pada penyitas kdrt. (Tesis) Universitas Gadjah Mada, Yogyakarta.

Hölzel, B.K., Ott, U., Gard, T., Hempel, H., Weygandt, M., Morgen, K., \& Vaitl, D. (2008). Investigation of mindfulness meditation practitioners with voxel-based morphometry. Social Cognitive and Affective Neuroscience, 3: 55-61. doi:10.1093/scan/nsm038

Humphrey, P., \& Harbin, J., (2010). An exploratory study of the effect of rewards and deadlines on academic procrastiantion in web-based classes. Academy of Educational Leadership Journal, 14(4): 91-97.

Idhom, A. M. (2015, 31 Mei). Ini alasan rektor ugm menolak penghapusan skripsi. Tempo. Diakses dari: http://m.tempo.co/ tanggal 15 Agustus 2015.

Jain, S., Swanick, S., Roesch, S.C., Mills, P.J., Bell, I., \& Schwartz, G.E. (2007) A randomized controlled trial of mindfulness meditation versus relaxation training: effects on distress, positive states of mind, rumination, and distraction. Annals of Behavioral Medicine, 33:11-21.

Kabat-Zinn, J. (1994). Wherever you go there you are. New York: Hyperion.

Kabat-Zinn, J. (2003). Mindfulness-Based Interventions in Context: Past, present, and future. Clinical psychology: Science and practice, 10(2): 144-156. doi: 10.1093/clipsy/bpg016

Kabat-Zinn, J. (2005). Full catastrophe living: Using the wisdom of your body and mind to face stress, pain, and illness (50 th Anniversary ed.). New York: Delta Trade Paperbacks.

Kaufman, K. A., Glass, C. R., \& Arnkoff, D.B. (2009). Evaluation of mindful sport performance enhancement (mpse): A new approach to promote flow in athletes. Journal of Clinical Sports Psychology, 4: 334-356

Keng, L., Smoski, M. J., Robins, C. J., Ekblad, A. G., \& Brantley, J. G. (2012) Mechanisms of change in mindfulness-based stress reduction: Self-compassion and mindfulness as mediators of intervention outcomes Journal of Cognitive Psychotherapy: An International Quarterly, 26(3): 270 280. doi: 10.1891/0889-8391.26.3.270.

Kenneth G. Rice, Greg J. Neimeyer, Jennifer M. Taylor. (2011). Efficacy of Coherence Therapy in the Treatment of procrastination and perfectionsm. Counseling Outcome Research and Evaluation Journal, 2(2), 126-136.

doi: $10.1177 / 2150137811417975$.

Klingsieck, K. B. (2013) Procrastination in different life-domains: Is procrastination domain specific?. Current Psychology, 32:175-185. doi: 10.1007/s12144-013-9171-8.

Knaus, W. (2010). End procrastination now! Get It done with a proven psychological approach. New York: McGraw Hill.

Luberto, C. M., Cotton, S., McLeish, A. C., Mingione, C. J., \& O'Bryan, E. M. 
(2014). Mindfulness skills and emotion regulation: The mediating role of coping self-efficacy. Mindfulness, 5: 373-380. doi: 10.1007/s12671-012-0190-6.

Lykins, E. L. B., \& Baer , R. A., (2009) Psychological functioning in a sample of long-term practitioners of mindfulness meditation. Journal of Cognitive Psychotherapy: An International Quarterly, 23 (3): 226 241.

Mackenzie, C.S., Poulin, P.A., \& SeidmanCarlson, R. (2006). A briefmindfulness based stress reduction intervention for nurses and nurse aides. Nursing Research, 19:105-9.

Maulia, D. (2011). Pelatihan belajar berdasar regulasi diri untuk menurunkan prokrastinaasi akademik pada mahasiswa. (Tesis). Universitas Gadjah Mada, Yogyakarta.

Negara, P. S. (2013). Hubungan antara usia, jenis kelamin, impulsiveness, mood, timing of rewards, and punishments, dan task aversiveness dengan prokrastinasi akademik mahasiswa. (Tesis). Universitas Gadjah Mada, Yogyakarta.

Nguyen, B., Steel, P., \& Ferrari, J. R. (2013). Procrastination's impact in the workplace and the workplace's impact on procrastination. International Journal of Selection and Assessment, 21(8): 388-399. doi: 10.1111/ijsa.12048.

Nicholson, L. \& Scharff, L. F. V. (2007). The Effects of procrastination and selfawareness on emotional responses. Psi Chi Journal of Undergraduate Research, 12(4): 139-145.

Ozer, B. U., Demir, A., \& Ferrari, J. R. (2009). Exploring academic procrastination among turkish students: Possible gender differences in prevalence and reasons. The
Journal of Social Psychology, 149(2), 241-257. doi: 10.3200/SOCP.149.2.241-257.

Ozer, B. U., Demir, A., \& Ferrari, J. R. (2013). Reducing academic procrastination through a group treatment program: A pilot study. Journal of Rational Emotive and Cognitive-Behavioral Therapy, 31:127135. doi: 10.1007/s10942-013-0165-0

Peper, E., Harvey, R., Lin, I., \& Duvvuri, P. (2014). Increase productivity, decrease procrastination, and increase energy. Biofeedback, 42(2): 82-87, doi: 10.5298/1081-5937-42.2.06

Peters, J. R. \& Erisman, S. M., Upton, B. T., Baer, R. A., \& Roemer, L. (2011) A preliminary investigation of the relationships between dispositional mindfulness and impulsivity. Mindfulness, 2: 228-235. doi: 10.1007/s12671-011-0065-2.

Peraturan Pemerintah Nomor 60 Tentang Pendidikan Tinggi (1999).

Primasari, T. A. (2016) Menikmati setiap moment: Meningkatkan subjective well-being remaja melalui program mindfulness remaja (prima). (Tesis). Universitas Gadjah Mada, Yogyakarta.

Priyudha, P. A. (2016) "Program young mindful warrior" untuk meningkatkan regulasi diri remaja yang mengalami adiksi game online. (Tesis). Universitas Gadjah Mada, Yogyakarta.

Pychyl, T. A. (2014). Procrastination: Why mindfulness Is crucial?. Psychology Today. Diakses dari https://www.psychologytoday.com/ blog/dont-delay/tanggal 15 Agustus 2015.

Rahimi, L., Ahmadean, H., Moslemi, B., Ghaderi, N., Khoshroei, M., (2014) The efficacy of mindfulness based stress reduction on the 
procrastination reduction nurses city of marivan. Zanko Journal Medical Science, 15(46): 29-39.

Ritonga D. A. (2012) Dinamika Prokrastinasi Mahasiswa Dalam Proses Menulis Skripsi. (Tesis) Universitas Gadjah Mada, Yogyakarta.

Rozental, A., \& Carlbring, P. (2013). Internet-based cognitive behavior therapy for procrastination: Study protocol for a randomized controlled trial. JMIR Research Protocols, 2, e46. doi: 10.2196/resprot.2801

Rozental, A., \& Carlbring, P. (2014). Understanding and treating procrastination: A review of a common self-regulatory failure. Psychology, 5, 1488-1500. doi: 10.4236/psych.2014.513160

Rozental, A., Forsström, D., Nilsson, S., Rizzo, A., \& Carlbring, P. (2014). Group versus Internet-based cognitive-behavioral therapy for procrastination: Study protocol for a randomized controlled trial. Internet Interventions, 1: 84-89. doi: 10.1016/j.invent.2014.05.005

Sani, F. \& Todman, J. (2006) Experimental design and statistics for psychology: A first course. [Versi Adobe Electronic Digital] ISBN: 1-4051-0024-9

Shadish, W. R., Cook, T. D. \& Campbell, D. T. (2002). Experimental and quasiexperimental designs for generalized causal inference. Boston, MA: Houghton Mifflin.

Sherlyn S. Jimenez, Barbara L. Niles , Crystal L. Park. (2010). A mindfulness model of affect regulation and depressive symptoms: Positive emotions, mood regulation expectancies, and self-acceptance as regulatory mechanisms. Journal of Personality and Individual Diferences. 49 (2010),
645-650. doi

10.1016/j.paid.2010.05.041

Siaputra, I. B., Prawitasari, J. E., Hastjarjo, T. D., \& Azwar, S. (2011). Subjective and projective measures of thesis writing procrastination: Real world and the sims world. Anima, 26(2): 128 -149 .

Sirois, F. M. (2014) Procrastination and stress: Exploring the role of selfcompassion. Self $\mathcal{E}$ Identity, 13(2): 128-145.

doi: 10.1080/15298868.2013.763404.

Sirois, F. \& Pychyl, T.A. (2013). Procrastination and the priority of short-term mood regulation: Consequences for future self. Social and Personality Psychology Compass, 7: 115-127. doi: 10.1111/spc3.12011.

Sirois, F. \& Pychyl, T.A. (2016). Porcrastination, emotion regulation, and well-being. Dalam Penulis (Ed) Procrastination, health, and well-being.

Sirois, F. M., \& Tosti, N. (2012). Lost in the moment? An investigation of procrastination, mindfulness, and well-being. Journal of RationalEmotive $\mathcal{E}$ Cognitive-Behavioral Therapy, 30: 237-248. doi: 10.1007/s10942-012-0151-y.

Solomon, L. J., \& Rothblum, E. D. (1984). Academic procrastination: Frequency and cognitive-behavioral correlates. Journal of Counseling Psychology, 31(4): 503-509. doi: 10.1037/0022-0167.31.4.503.

Stahl, B. \& Goldstein, E. (2009). A mindfulness-based stress reduction workbook. Oakland, CA: New Harbinger Publication, Inc

Steel, P.D.G. (2002) The measurement and nature of procrastination. (Tesis). University of Minnesota, Minnesota.

Steel, P. (2007). The nature of procrastination: A meta-analytic and theoretical review of quintessential 
self-regulatory failure. Psychological Bulletin, 133(1): 65-94. doi: 10.1037/0033-2909.133.1.65

Steel, P. (2012) The procrastination equation: How to stop putting things off and start getting stuff done. New York; HarperCollins.

Steel, P. \& Konig, C. J. (2006) Integrating theories of motivation. Academic Management Review, 31(4):889-913.

Szabo, T. G., Long, D. M., Villatte, M., \& Hayes, S. C. (2015) Mindfulness in contextual cognitive-behavioral models. Dalam Brown, K. W., Creswell, J. D., \& Ryan, R. M. (Ed) Handbook of mindfulness: Theory, research, and practice. New York: The Guilford Press.

Tice, D. M., \& Baumeister, R. F. (1997) Longitudinal study of procrastination, performance, stress, and health: The costs and benefits of dawdling. Psychological science, 8(6): .454-458. doi: 10.1111/j.14679280.1997.tb00460.x

VanVaugt, M. K. (2015), Cognitive benefits of mindfulness meditation. Dalam Brown, K. W., Creswell, J. D., \& Ryan, R. M. (Ed) Handbook of mindfulness: Theory, research, and practice. New York: The Guilford Press.

Veresova, M. (2013). Procrastination, stress, and coping among primary school teachers. Procedia-Social and Behavioral Sciences, 106(20): 21312138.

doi:10.1016/j.sbspro.2013.12.243.

Watkins, E. R. (2015) Mindfulness in the context of processing mode theory. Dalam Brown, K. W., Creswell, J. D., \& Ryan, R. M. (Ed) Handbook of mindfulness: Theory, research, and practice. New York: The Guilford Press.

Wei, M., Tsai, P., Lannin, D. G., Du, Y., \&
Tucker, J. R. (2015) Mindfulness, psychological flexibility, and counseling self-efficacy: Hindering self-focused attention as a mediator. The Counseling Psychologist, 43(1): 3963. doi: 10.1177/0011000014560173

Wohl, M. J. A., Pychyl, T. A., \& Bennet, S. H. (2010). I forgive myself, now i can study: How self-forgiveness for procrastinating can reduce future procrastination. Personality and Individual Differences, 48: 803-808. doi: 10.1016/j.paid.2010.01.029.

Widyatmoko, C. S. (2010) Terapi berdasar psikoedukasi dan mindfulness untuk menigkatkan gairah dan bangkitan seksual pada perempuan. Tesis. Universitas Gadjah Mada, Yogyakarta.

Tang, Y. \& Posner, M. I (2015) Mindfulness in the context of the attention system. Dalam Brown, K. W., Creswell, J. D., \& Ryan, R. M. (Ed) Handbook of mindfulness: Theory, research, and practice. New York: The Guilford Press.

Zeidan F., Johnson, S. K., Diamond, B. J., David, Z., \& Goolkasian, P. (2010) Mindfulness meditation improves cognition: Evidence of brief mental training. Consciousness and Cognition, 19: 597-605. doi: 10.1016/ j.concog.2010.03.014. 